\title{
Obstetrical Outcomes of Head and Neck (Nonthyroid) Cancers: A 27-Year Retrospective Series and Literature Review
}

\author{
Ernesto Antonio Figueiró-Filho, MD, PhD ${ }^{1}$ Richard P. Horgan, MD ${ }^{2}$ Nidal Muhanna, MD, PhD ${ }^{3,4}$ \\ Jacqueline Parrish, BSC ${ }^{1}$ Jonathan C. Irish, MD, MSc $^{2}$ Cynthia V. Maxwell, MD ${ }^{1}$
}

${ }^{1}$ Division of Maternal-Fetal Medicine, Department of Obstetrics and Gynecology, Mount Sinai Hospital, University of Toronto, Toronto, Ontario, Canada

2 Department of Obstetrics and Gynecology, University Hospital Kerry, Tralee, County Kerry, Ireland

${ }^{3}$ Division of Head and Neck Oncology and Reconstructive Surgery, Department of Otolaryngology-Head and Neck Surgery, University of Toronto, Toronto, Ontario, Canada

${ }^{4}$ Department of Otolaryngology, Tel Aviv University, Tel Aviv, Israel

\author{
Address for correspondence Ernesto Antonio Figueiró-Filho, MD, \\ PhD, Division of Maternal-Fetal Medicine, Department of Obstetrics \\ and Gynecology, Mount Sinai Hospital, University of Toronto, 600 \\ University Avenue, Toronto, ON - M5G $1 \times 5$, Canada \\ (e-mail: eafigueiro@gmail.com; \\ ernesto.figueiro@mail.utoronto.ca).
}

Am J Perinatol Rep 2019;9:e15-e22.

\begin{abstract}
Keywords

- head and neck

- cancer

- pregnancy

- perinatal

- outcomes

Objective To describe the clinical presentation and obstetrical outcomes of nonthyroid head and neck cancers (HNCs), and to review literature on this rare condition in pregnancy.

Study Design Pregnant women with nonthyroid HNC were identified retrospectively from 1990 to 2017. Maternal, neonatal, pregnancy, and demographic data were collected. A review of the literature from January 1980 to May 2018 was performed. Results Over the 27-year time period, 16 women with history of nonthyroid HNC were identified ( 9 diagnosed during and 7 diagnosed before current pregnancy). The cases were analyzed in detail and the most updated review of management of each type of HNC was provided.

Conclusions HNCs are rare with diagnosis and management challenges during pregnancy. In this series, the cases diagnosed and managed previously to pregnancy presented better perinatal outcomes than the cases presented during pregnancy. The maternal outcomes appeared similar for HNC diagnosed before or after pregnancy.
\end{abstract}

Worldwide, there are over half a million cases of head and neck cancer (HNC) diagnosed each year. ${ }^{1}$ HNC describes a range of tumors that arise in the head and neck region which includes the oral cavity, pharynx, larynx, nasal cavity, paranasal sinuses, thyroid, and salivary glands. ${ }^{2}$ While these cancers are the fifth most common worldwide, ${ }^{3}$ they are uncommon in young women. ${ }^{4}$ The incidence of HNC in younger females has increased, ${ }^{5,6}$ which may account for the increase in cases with pregnancy. ${ }^{7}$

The most common invasive cancers diagnosed during pregnancy are breast, melanoma, hematologic, cervix/uterus, and thyroid. ${ }^{8-11}$ Guidelines for management of thyroid cancer in pregnancy are available., ${ }^{72}$ In contrast, there is limited information on nonthyroid HNC and pregnancy. ${ }^{13-16}$

As many medical teams are involved in the care of women who develop HNC in pregnancy, a coordinated, multidisciplinary approach including obstetrics, surgical and medical oncology, neonatology, specialized nursing, social work, and diagnostic imaging is essential in the counseling and management.

The aim of the present study is to describe the clinical presentation and outcomes of nonthyroid HNC, as well as to review literature on this rare condition in pregnancy. received

September 4, 2018 accepted after revision November 5, 2018
DOI https://doi.org/ 10.1055/s-0039-1677876. ISSN 2157-6998.
Copyright $\odot 2019$ by Thieme Medical Publishers, Inc., 333 Seventh Avenue, New York, NY 10001, USA. Tel: +1(212) 584-4662.
License terms

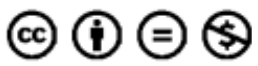




\section{Methods}

Pregnant patients with HNC were identified from a major maternal fetal medicine and head and neck oncology center retrospectively using hospital databases. Cases included nonthyroid HNCs (oral cavity, pharynx, larynx, nasal cavity, paranasal sinuses, salivary glands, eye, or ear) from 1990 to 2017. Maternal, neonatal, pregnancy, and demographic data were collected on a standardized form. Oncology data included tumor type, anatomical location, clinical/surgical management, time of diagnosis in relation to pregnancy, and maternal/neonatal outcomes. Hospital ethics board approval was obtained.

A review of the literature from January 1980 to May 2018 was performed using MEDLINE, EMBASE, and the gray literature. Reference lists from identified articles and relevant reviews were searched for articles not found in the above databases. Key words used were oral cavity, pharynx, larynx, nasal cavity, paranasal sinuses, nonthyroid, salivary glands and pregnancy, perinatal outcome, pregnant women, prenatal, and antenatal. Limits were set to include human studies only. Studies were included if they (1) investigated humans; (2) described nonthyroid cancers during pregnancy; (3) looked at obstetrical/perinatal outcomes; (4) were observational cross-sectional studies; (5) were wellreported case series; and (5) published in a peer-reviewed publication. Studies were excluded if they investigated nonhuman species; did not describe concomitancy of nonthyroid HNCs with pregnancy; described thyroid cancer during pregnancy; were interventional; and were conference publications or were not published in English.

\section{Results}

Over the specified time period, 16 women with a current or a past history of HNCs, excluding thyroid cancer, were identified. The anatomical location of these tumors is shown in -Table 1. Of the 16 cases, 9 were diagnosed during pregnancy and 7 were diagnosed before the current pregnancy. Details are shown in - Tables 2 and $\mathbf{3}$.

The 9 cases diagnosed during pregnancy (-Table 2) consisted of 3 tongue cancers, 1 cancer of the nasal cavity, 3 nasopharyngeal cancers (NPCs), 1 acoustic neuroma, and 1

Table 1 Summary of tumor location-nonthyroid head and neck cancers diagnosed during and prior to pregnancy

\begin{tabular}{|l|l|}
\hline Tumor location & Number \\
\hline Tongue & 3 \\
\hline Nasal cavity & 1 \\
\hline Nasopharynx & 5 \\
\hline Trachea & 1 \\
\hline Salivary glands & 2 \\
\hline Larynx & 1 \\
\hline Ear & 2 \\
\hline Mandible & 1 \\
\hline
\end{tabular}

mandible sarcoma. The mean maternal age at diagnosis was 33 years (range: 19-39 years), the mean gestational age at diagnosis was 18.5 weeks (range: 5-32 weeks). The mean gestational age at delivery was 32 weeks (range: 23-37.4 weeks). Only one patient (with nasopharyngeal carcinoma) was identified as a tobacco user, and had ceased this behavior 1 year prior to pregnancy.

All cases of HNC during pregnancy in our series were singleton gestations. Three patients were induced before term to expedite the cancer treatment and management. One patient opted for a termination of pregnancy at 23 weeks for social reasons related to her cancer diagnosis. Three patients had cesarean birth, one at term and two prior to 37 weeks' gestation. One of the preterm deliveries by cesarean was due to antepartum hemorrhage and the second was to expedite postpartum chemotherapy for an aggressive mandibular osteosarcoma.

Antepartum surgical management of HNC occurred in three cases. Chemotherapy was administered postpartum for all patients for whom it was indicated.

There were seven cases diagnosed prior to pregnancy (-Table 3). The mean time between the diagnosis and pregnancy was 8.5 years (range: 2-15 years). The mean gestational age at delivery was 38.5 weeks (range: $33-41.1$ weeks) with a mean birthweight of $2,787 \mathrm{~g}$ (range: 1,450$3,965 \mathrm{~g}$ ). One case listed as tracheal cancer was an adenoid cystic carcinoma and could be considered as a minor salivary gland malignancy. All patients had undergone previous surgery and radiation therapy. The patient with nasopharyngeal carcinoma also had chemotherapy for a recurrence prior to pregnancy. The case of acoustic neuroma was surgically treated, although a residual tumor was identified on the left jugular foramen.

Among the NHC cases preceding the current pregnancy, there were five singleton pregnancies and one set of dichorionic/diamniotic (DCDA) twins. Of the singleton pregnancies, four were uncomplicated, one presented oligohydramnios and abnormal umbilical artery Doppler velocimetry at term and one developed late onset gestational hypertension. Four singleton pregnancies had full-term vaginal deliveries, and the two patients were delivered by cesarean birth (DCDA twins and the patient with abnormal Doppler findings).

The twin pregnancy was complicated by a short cervix for which a cervical cerclage was placed in the second trimester (19 weeks). Contractions commenced at 33 weeks' gestation, the cerclage was removed and an emergency cesarean section was performed for abnormal fetal status. The birth weights were 1,830 and $1,450 \mathrm{~g}$ for twin $\mathrm{A}$ and twin $\mathrm{B}$, respectively. There were no tumor recurrences during these pregnancies and no maternal complications.

\section{Discussion}

This study analyzed the maternal, medical, and pregnancy outcomes of 16 patients with primary HNC diagnosed during and before pregnancy. In this series, there were five cases of nasopharyngeal carcinoma, two cases of the major or minor salivary glands, and three tongue carcinomas. While this is a 


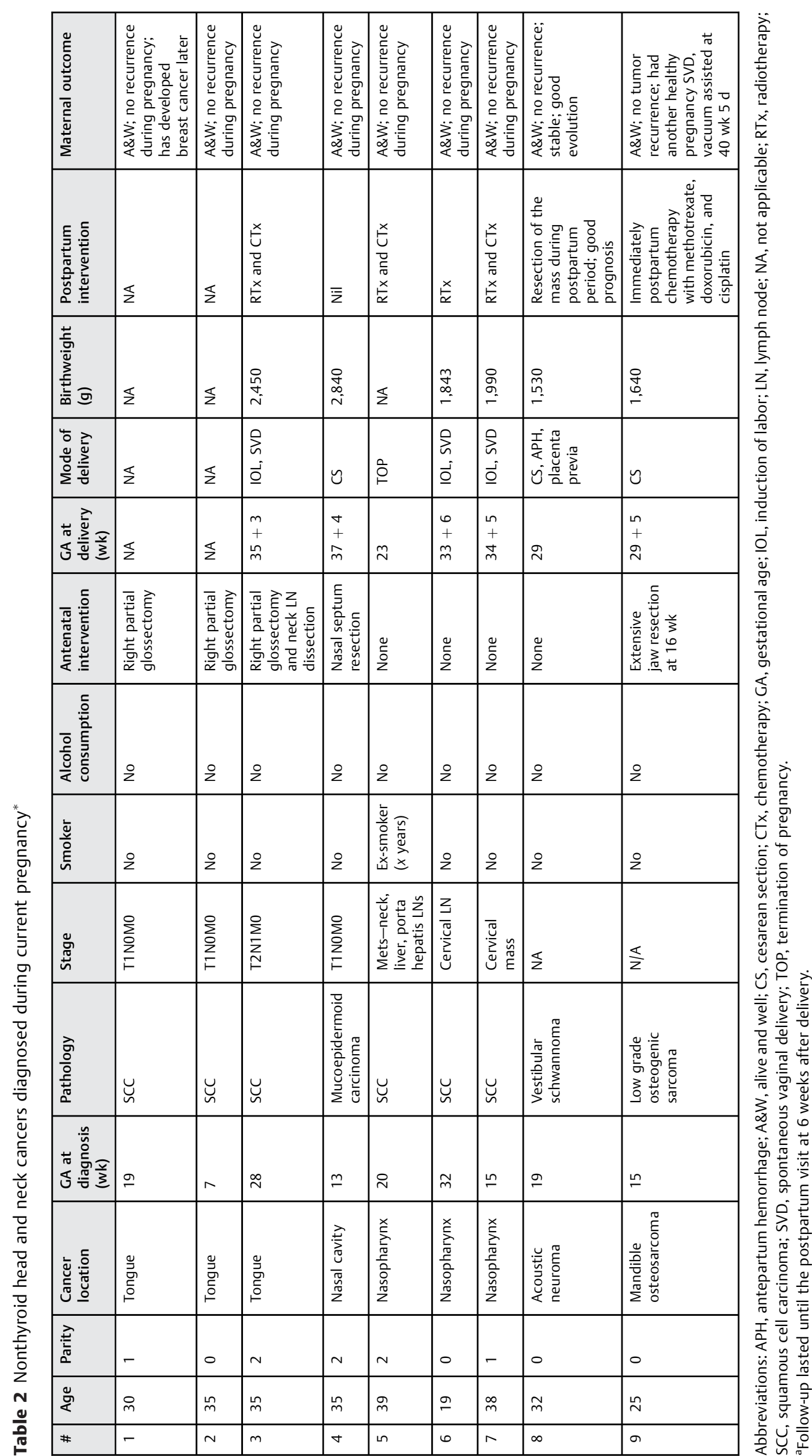



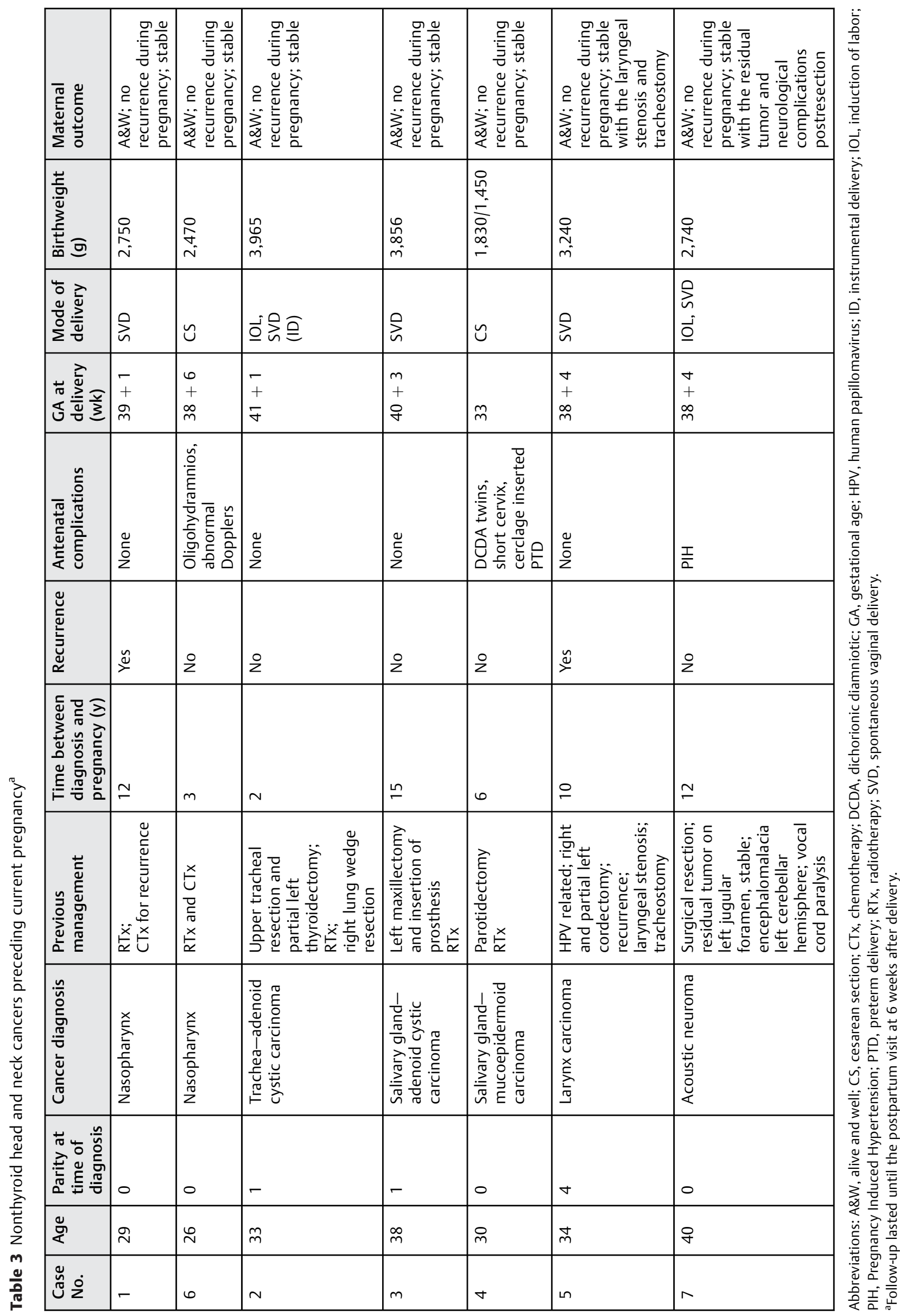
small series, we note that in several cases the diagnosis of HNC during pregnancy impacted decision making in delivery planning. HNCs are generally treated with a combination of surgery, radiation, and chemotherapy. ${ }^{7,15}$ These treatments create some risk for the fetus, raising complex ethical and moral issues. ${ }^{17}$ Formulating the care plan needs to involve the patient, her family, and all members of the medical care teams including neonatology, considering other maternal and medical concerns, gestational age, and pre-existing fetal issues.

Ideally the treatment plan can be implemented safely for the mother and in a manner that minimizes harm to the fetus. ${ }^{7}$ The option of termination of pregnancy should be discussed not only for social reasons, but also in situations where there is potential for maternal mortality. ${ }^{17}$ The care team should also consider circumstances where perimortem caesarean birth (depending on gestational age) may be a lifesaving measure for the fetus, in a circumstance where maternal mortality is likely to occur.

Radiographic studies: Radiographic technologies including computed tomography (CT) and magnetic resonance imaging (MRI) play an integral role in establishing the extent of local invasion, lymph node involvement, and/or metastatic spread. Lungs, liver, and bone are the most common sites for metastatic spread of HNC. A threshold of $100 \mathrm{mGy}$ at any time during gestation should be considered as a practical threshold for the induction of congenital defects, ${ }^{18}$ although recommendations not to exceed $50 \mathrm{mGy}(5 \mathrm{rad})$ are also found. ${ }^{19}$ A head CT has a dose of $0.1 \mathrm{mGy}(10 \mathrm{mrad})$ which is well below this threshold and should not be delayed when indicated during pregnancy. ${ }^{20,21}$ Malformations will occur after an exposure to more than $2 \mathrm{~Gy}$ and abortion after 3Gy, in most exposed fetuses. ${ }^{22}$ MRI is an acceptable imaging modality given the lack of radiation exposure, but in some centers may be less accessible than CT.

Radiation therapy: Other effects of radiation in pregnancy include fetal growth restriction, future intellectual disability, leukemia, and other cancers in later life. ${ }^{23}$ To this end, it is generally avoided, as reflected in our case series, and delivery is often performed early so that radiotherapy can be instigated. Radiotherapy has been used safely during pregnancy, ${ }^{24}$ but appropriate recommendations should be followed to protect the fetus. ${ }^{19}$

Diagnosis and surgery during pregnancy: Pregnancy may mask presenting symptoms of HNC depending on the tumor location and may delay investigation or diagnosis. An examination under anesthesia or definitive surgery should be performed if indicated irrespective of trimester of pregnancy as recommended by the American College of Obstetricians and Gynecologists. ${ }^{25}$ HNCs in particular pose several challenges for treatment. These include the anatomic complexity of the head and neck area, the significance of optimizing the function of the area involved, and the obtainment of a good cosmetic result. ${ }^{7,26}$ HNCs are generally treated with a combination of surgery, radiation, and chemotherapy, ${ }^{7}$ yet early-stage diseases are generally treated with primary surgery or radiotherapy alone. In general terms, surgery is often used for more accessible masses as in the oral cavity ${ }^{13}$ and radiotherapy where the access is more difficult. ${ }^{22,26}$ This is reflected in our series where tongue tumors were treated surgically while NPCs were more often treated with radiotherapy. For more advanced disease and also for certain histology types, chemotherapy is typically integrated into the management plan. ${ }^{27}$

Chemotherapy in pregnancy: Usually, chemotherapy should be postponed to second/third trimesters, avoiding fetal exposure during first trimester, unless advanced/aggressive and/or progressive disease is identified early in pregnancy and a delay in treatment may negatively affect maternal survival. ${ }^{28,29}$ Where possible, chemotherapy should be deferred until after the first trimester. ${ }^{30}$ Chemotherapy during pregnancy is still controversial as cytotoxic drugs may interfere with organogenesis, in general between 2 and 8 weeks after conception. ${ }^{31}$ The safety of chemotherapy during pregnancy is based upon a few case series and not all multiagent regimens have been studied in detail. ${ }^{32,33}$ A 10-year retrospective study in Belgium focusing in pregnant women with cancer, prenatally exposed to cytotoxic treatment, demonstrated that more than $50 \%$ of neonates were admitted to the neonatal intensive care unit due to preterm labor. ${ }^{9}$

Chemotherapy protocols combining cyclophosphamide and an anthracycline have been used during pregnancy by the end of the first trimester and were found to be safe. ${ }^{28-30}$ During second/third trimesters, most multidrug chemotherapy protocols may be administered without an apparent increase in the risk for fetal malformations. ${ }^{28-30}$ The preferred scheme should be a weekly fractionated-dose chemotherapy which permits ease of monitoring, and interruption of treatment if necessary. Such chemotherapeutic approaches appear to be safe; therefore, data regarding their efficacy for the maternal cancer are lacking. ${ }^{28-30}$

\section{Management of Specific Sites in Nonthyroid Head and Neck Cancers during Pregnancy}

Nasopharyngeal cancer: NPC is a very rare cancer in North America and Europe with an incidence of 0.5 to 2 per $100,000^{34}$ but more common in Asia where the incidence is as high as 25 to 50 per $100,000 .{ }^{35}$ All patients with nasopharynx cancer in our case series were of Asian descent. NPC in pregnancy is described mainly through case reports. Star and Malee report a case of stage four NPCs, ${ }^{36}$ in which the patient labored and delivered at 31 weeks. The patient underwent four courses of chemoradiation but died from her disease within 6 months. Yan et al reported on 27 cases in China from a 14-year period from 1958 to 1972; these included nine cases discovered to be pregnant during radiotherapy and 18 cases who became pregnant after treatment. The outcome of the group with current disease and pregnancy was poor compared with the group with a history of disease with a 5 -year survival of 11 versus $83 \% .{ }^{37}$

Tongue cancer: Oral cavity cancer typically occurs in older men associated with tobacco and alcohol use, but there appears to be an increase in incidence in cancer of the tongue in younger patients. ${ }^{5,38,39}$ This may be related to other factors such as marijuana use and viral infection. ${ }^{40,41}$ Reviewing the available case reports, $4,14,15,24,40,42-51$ we infer that pregnant women with tongue cancers are treated 
similarly to nonpregnant patients. Mhallem et al described five cases of tongue cancer during pregnancy. ${ }^{24}$ They reviewed the literature up to that point and found a further 12 cases in the literature, adding up to 17 cases with a wide variation in management. ${ }^{24}$ Most recently, Tagliabue et al described six more cases of tongue cancer during pregnancy, which results in 31 cases described so far. $4,14,15,24,40,42-51$ Yokoshima et al in reporting the surgical management of tongue cancer during pregnancy suggest that less than optimal management may result in a worse prognosis. ${ }^{44}$

Nasal cavity cancer: Tumors of the nasal cavity occur most common in elderly men. ${ }^{52}$ Numerous tumor histological types exist, the most common of which are squamous cell carcinoma and adenocarcinoma. Mucoepidermoid carcinoma as in our case arises from minor salivary glands. Both surgery and radiotherapy play an important role in management. ${ }^{7,26}$ In this report, the patient was diagnosed with nasal cavity mucoepidermoid carcinoma at 13 weeks, was treated with surgical resection of the nasal septum, and had a caesarean birth at term, not requiring further chemotherapy/radiotherapy during the postpartum period.

Salivary gland tumors: Salivary gland tumors comprise less than $10 \%$ of HNCs and usually follow a benign clinical course. The salivary gland system includes major glands (parotid, submandibular, and sublingual) and minor glands which can be found throughout the mouth and upper digestive tract. ${ }^{53}$ The most common site of salivary gland tumors is the parotid gland, which accounts for $\sim 80 \%$ of these tumors, ${ }^{53}$ one-fourth of which are malignant. ${ }^{54}$ Tumors of the other salivary glands including the minor glands vary considerably in the proportion of malignant and the likelihood of having metastases and recurrence. The most common malignant salivary gland cancer is mucoepidermoid carcinoma, followed by adenoid cystic carcinoma. Together they make up over $50 \%$ of all malignant tumors of the salivary glands. ${ }^{55}$ In a retrospective study of 78 patients with the major salivary gland, positive prognostic factors included female gender, younger age and lack of perineural invasion, lack of facial nerve involvement, and negative nodes. ${ }^{56}$

Acoustic neuroma: Acoustic neuromas, also called vestibular schwannomas, acoustic neurinomas, or acoustic neurilemmomas, usually arise from the vestibular portion of the eighth cranial nerve, and are found more frequently in women. They are essentially benign. ${ }^{57}$ The symptoms of acoustic neuromas may confound with common complaints in pregnant women due to the nonspecific nature of these signs, usually described as tinnitus, headache, nausea, and vomiting, and may cause delay in diagnosis. During the third trimester, headache and elevation of the blood pressure might be mistaken as preeclampsia. ${ }^{58,59}$ Our case series identified two cases of acoustic neuroma, one diagnosed prior to the current pregnancy and the other during pregnancy. The patient presenting during pregnancy delivered prematurely at 29 weeks due to antepartum hemorrhage. She required surgery for her tumor in the immediate postpartum period. The other patient had the acoustic neuroma resected 12 years before being pregnant and in spite of a residual tumor in a difficult area (jugular foramen), no recurrence occurred during gestation and she delivered at term ( 38 weeks 4 days). A recent review listed only 31 cases of vestibular schwannomas diagnosed during pregnancy. ${ }^{57}$ The most frequent symptom was hearing loss and the diagnosis was mostly in the second or third trimester. Six cases required surgical resection prior to delivery. Most of the deliveries were at term or near term. ${ }^{57}$

Trachea cancer: The patient in our series developed adenoid cystic carcinoma of trachea 2 years before her current pregnancy. The management of the tumor required surgical intervention with tumor resection with partial left thyroidectomy and right-lung wedge resection. Radiotherapy was part of the treatment plan. The pregnancy after the cancer treatment went well and the baby was delivered at term with no maternal or neonatal complications. Similarly to our case, Abike et $\mathrm{al}^{60}$ described a 28-year-old patient at 28 weeks diagnosed with primary tracheal adenoid cystic carcinoma. The patient underwent a thoracotomy and surgical removal of tracheal tumor immediately following the diagnosis. The baby was delivered by cesarean section at 39 weeks and there was no recurrence of the tumor during the gestational period.

Mandible sarcoma: The case of mandible cancer in our series was an osteosarcoma diagnosed at 15 weeks. Patient had an extensive jaw resection and reconstruction at 16 weeks and had premature birth at 29 weeks by caesarean to expedite an aggressive chemotherapy regimen deemed unsafe for fetal exposure. In spite of the aggressive management during pregnancy, both the mother and baby had satisfactory outcomes. The same patient had another healthy pregnancy 3 years after the first and was delivered at term with a successful trial of labor, without maternal or fetal complications. We could identify only one other case of sarcoma of mandible during pregnancy reported in the literature. Stroncek et $\mathrm{al}^{61}$ reported a 15 -year-old pregnant patient with a mandible osteosarcoma diagnosed at 20 weeks. The patient underwent extensive surgery. The pregnancy was terminated to accommodate chemotherapy. Unfortunately there was poor response to the chemotherapy and the patient died 1 month after the diagnosis.

Larynx cancer: The occurrence of primary cancer of the larynx during pregnancy is very rare. ${ }^{62,63}$ In our series, the patient with laryngeal carcinoma was diagnosed 10 years before the current pregnancy with human papillomavirus related etiology. The patient was treated surgically with right and partial-left cordectomy. The tumor recurred and other surgical interventions were necessary. There was no recurrence during the pregnancy, but the residual laryngeal stenosis and tracheostomy were important components of delivery and obstetric anesthesia planning. The pregnancy outcome was uncomplicated. In 1980, Ferlito and Nicolai ${ }^{62}$ reported a case of laryngeal squamous cell carcinoma in a pregnant woman, who presented with progressive hoarseness and was eventually diagnosed in the second trimester. The patient was treated with laryngectomy and right-sided radical neck dissection after a term delivery. In 1995, Pytel et $\mathrm{al}^{63}$ reported a case of a 33-year-old woman carrying a twin gestation, with supraglottic laryngeal cancer, detected during the first trimester. This patient underwent supraglottic laryngectomy during 
pregnancy without complications and no recurrence and the twins were delivered at term.

\section{Conclusion}

HNCs are rare and present diverse management challenges during pregnancy. As symptoms can be nonspecific, the diagnosis may be difficult to establish. The involvement of obstetric, anesthesia, and neonatology teams, in conjunction with medical, surgical, and radiation oncology teams, is critical. The aim is to correctly diagnose, stage, and plan treatments for HNC during pregnancy, while trying to ensure optimal maternal and neonatal outcomes. ${ }^{64}$

Although our numbers are too small to draw major conclusions, we did observe more iatrogenic preterm births for HNC during pregnancy (mean gestational age and birthweight of 32 weeks and 2,048 g, respectively) as compared with the cases diagnosed and treated prior to pregnancy (38.5 weeks and 2,787 g, respectively). We observed similar maternal outcomes for women diagnosed during and before pregnancy.

In the absence of larger, prospective studies, reports and case series will continue to be important in informing patients, families, and caregivers about the management of HNC during pregnancy. While our series is limited by small numbers, we observed that it is possible to provide timely treatment to pregnant women with HNC with the support of a multidisciplinary team.

\section{Conflict of Interest}

None

\section{References}

1 Jemal A, Bray F, Center MM, Ferlay J, Ward E, Forman D. Global cancer statistics. CA Cancer J Clin 2011;61(02):69-90

2 Sankaranarayanan R, Masuyer E, Swaminathan R, Ferlay J, Whelan S. Head and neck cancer: a global perspective on epidemiology and prognosis. Anticancer Res 1998;18(6B):4779-4786

3 Parkin DM, Bray F, Ferlay J, Pisani P. Global cancer statistics, 2002. CA Cancer J Clin 2005;55(02):74-108

4 Lasaridis N, Tilaveridis I, Karakasis D. Management of a carcinoma of the tongue during pregnancy: report of case. J Oral Maxillofac Surg 1996;54(02):221-224

5 Schantz SP, Yu GP. Head and neck cancer incidence trends in young Americans, 1973-1997, with a special analysis for tongue cancer. Arch Otolaryngol Head Neck Surg 2002;128(03): 268-274

6 Lingen M, Sturgis EM, Kies MS. Squamous cell carcinoma of the head and neck in nonsmokers: clinical and biologic characteristics and implications for management. Curr Opin Oncol 2001;13 (03):176-182

7 Bradley PJ, Raghavan U. Cancers presenting in the head and neck during pregnancy. Curr Opin Otolaryngol Head Neck Surg 2004; 12(02):76-81

8 Cottreau CM, Dashevsky I, Andrade SE, et al. Pregnancy-associated cancer: a U.S. population-based study. J Womens Health (Larchmt) 2018. DOI: 10.1089/jwh.2018.6962

9 Van Calsteren K, Heyns L, De Smet F, et al. Cancer during pregnancy: an analysis of 215 patients emphasizing the obstetrical and the neonatal outcomes. J Clin Oncol 2010;28(04): 683-689
10 Stensheim H, Møller B, van Dijk T, Fosså SD. Cause-specific survival for women diagnosed with cancer during pregnancy or lactation: a registry-based cohort study. J Clin Oncol 2009;27(01):45-51

11 Gibelli B, Zamperini P, Proh M, Giugliano G. Management and follow-up of thyroid cancer in pregnant women. Acta Otorhinolaryngol Ital 2011;31(06):358-365

12 Boucek J, de Haan J, Halaska MJ, et al; International Network on Cancer, Infertility, and Pregnancy. Maternal and obstetrical outcome in 35 cases of well-differentiated thyroid carcinoma during pregnancy. Laryngoscope 2018;128(06):1493-1500

13 Layton SA, Rintoul M, Avery BS. Oral carcinoma in pregnancy. Br J Oral Maxillofac Surg 1992;30(03):161-164

14 Cheung EJ, Wagner H Jr, Botti JJ, Fedok F, Goldenberg D. Advanced oral tongue cancer in a 22-year-old pregnant woman. Ann Otol Rhinol Laryngol 2009;118(01):21-26

15 Chow VL, Chan JY, Ng RW, Wei WI. Management of head and neck tumours during pregnancy: case report and literature review. Asian J Surg 2008;31(04):199-203

16 Kiciński K, Skorek A, Stankiewicz C. Managment of head and neck cancers during pregnancy [in Polish]. Otolaryngol Pol 2011;65 (05):326-332

17 Kennedy S, Yudkin P, Greenall M. Cancer in pregnancy. Eur J Surg Oncol 1993;19(05):405-407

18 Streffer C, Shore R, Konermann G, et al. Biological effects after prenatal irradiation (embryo and fetus). A report of the International Commission on Radiological Protection. Ann ICRP 2003;33 (1-2):5-206

19 Stovall M, Blackwell CR, Cundiff J, et al. Fetal dose from radiotherapy with photon beams: report of AAPM Radiation Therapy Committee Task Group No. 36. Med Phys 1995;22(01):63-82

20 Chen MM, Coakley FV, Kaimal A, Laros RK Jr. Guidelines for computed tomography and magnetic resonance imaging use during pregnancy and lactation. Obstet Gynecol 2008;112(2, Pt 1):333-340

21 Lowe SA. Diagnostic radiography in pregnancy: risks and reality. Aust N Z J Obstet Gynaecol 2004;44(03):191-196

22 Mayr NA, Wen BC, Saw CB. Radiation therapy during pregnancy. Obstet Gynecol Clin North Am 1998;25(02):301-321

23 Kal HB, Struikmans H. Radiotherapy during pregnancy: fact and fiction. Lancet Oncol 2005;6(05):328-333

24 Mhallem Gziri M, Han SN, Van Calsteren K, et al. Tongue cancers during pregnancy: case reports and review of literature. Head Neck 2013;35(04):E102-E108

25 ACOG Committee on Obstetric Practice. ACOG Committee Opinion No. 474: nonobstetric surgery during pregnancy. Obstet Gynecol 2011;117(2, Pt 1):420-421

26 Falkenberry SS. Cancer in pregnancy. Surg Oncol Clin N Am 1998; 7(02):375-397

27 Pignon JP, le Maître A, Maillard E, Bourhis J; MACH-NC Collaborative Group. Meta-analysis of chemotherapy in head and neck cancer (MACH-NC): an update on 93 randomised trials and 17,346 patients. Radiother Oncol 2009;92(01):4-14

28 Koren G, Carey N, Gagnon R, Maxwell C, Nulman I, Senikas V. Cancer chemotherapy and pregnancy. J Obstet Gynaecol Can 2013;35(03):263-278

29 Peccatori FA, Azim HA Jr, Orecchia R, et al; ESMO Guidelines Working Group. Cancer, pregnancy and fertility: ESMO Clinical Practice Guidelines for diagnosis, treatment and follow-up. Ann Oncol 2013;24(Suppl 6):vi160-vi170

30 Azim HA Jr, Peccatori FA. Managing cancer during pregnancy: what evidence do we have? Pol Arch Med Wewn 2011;121(1-2):29-34

31 Garofalo S, Degennaro VA, Salvi S, et al. Perinatal outcome in pregnant women with cancer: are there any effects of chemotherapy? Eur J Cancer Care (Engl) 2017;26(06). doi: 10.1111/ ecc. 12564

32 Balsat M, Etienne M, Elhamri M, Hayette S, Salles G, Thomas X. Successful pregnancies in patients with BCR-ABL-positive leukemias treated with interferon-alpha therapy during the tyrosine kinase inhibitors era. Eur J Haematol 2018;101(06):774-780 
33 Hockertz T, Velickovic M. Successful spontaneous pregnancy after treatment for ewing sarcoma including sacrectomy. Case Rep Obstet Gynecol 2018;2018:2484036

34 Vokes EE, Liebowitz DN, Weichselbaum RR. Nasopharyngeal carcinoma. Lancet 1997;350(9084):1087-1091

35 Lee AW, Foo W, Mang O, et al. Changing epidemiology of nasopharyngeal carcinoma in Hong Kong over a 20-year period (1980-99): an encouraging reduction in both incidence and mortality. Int J Cancer 2003;103(05):680-685

36 Star J, Malee MP. Pregnancy complicated by nasopharyngeal carcinoma. Obstet Gynecol 1999;94(5, Pt 2):845

37 Yan JH, Liao CS, Hu YH. Pregnancy and nasopharyngeal carcinoma: a prognostic evaluation of 27 patients. Int J Radiat Oncol Biol Phys 1984;10(06):851-855

38 Park JO, Sun DI, Cho KJ, Joo YH, Yoo HJ, Kim MS. Clinical outcome of squamous cell carcinoma of the tongue in young patients: a stagematched comparative analysis. Clin Exp Otorhinolaryngol 2010;3 (03):161-165

39 Patel SC, Carpenter WR, Tyree S, et al. Increasing incidence of oral tongue squamous cell carcinoma in young white women, age 18 to 44 years. J Clin Oncol 2011;29(11):1488-1494

40 Eliassen AM, Hauff SJ, Tang AL, et al. Head and neck squamous cell carcinoma in pregnant women. Head Neck 2013;35(03):335-342

41 Llewellyn CD, Johnson NW, Warnakulasuriya KA. Risk factors for squamous cell carcinoma of the oral cavity in young people-a comprehensive literature review. Oral Oncol 2001;37(05):401-418

42 Tagliabue M, Elrefaey SH, Peccatori F, et al. Tongue cancer during pregnancy: surgery and more, a multidisciplinary challenge. Crit Rev Oncol Hematol 2016;98:1-11

43 Unsworth JD, Baldwin A, Byrd L. Systemic lupus erythematosus, pregnancy and carcinoma of the tongue. BMJ Case Rep 2013 (e-pub ahead of print). Doi: 10.1136/bcr-2013-008864

44 Yokoshima K, Nakamizo M, Sakanushi A, et al. Surgical management of tongue cancer during pregnancy. Auris Nasus Larynx 2012;39(04):428-430

45 Atabo A, Bradley PJ. Management principles of head and neck cancers during pregnancy: a review and case series. Oral Oncol 2008;44(03):236-241

46 Tapisiz OL, Gungor T, Ustunyurt E, Ozdal B, Bilge U, Mollamahmutoglu L. An unusual case of lingual alveolar soft part sarcoma during pregnancy. Taiwan J Obstet Gynecol 2008;47(02):212-214

47 Dumper J, Kerr P. Recurrent squamous cell carcinoma of the tongue in pregnancy. J Otolaryngol 2005;34(04):242-243

48 Koike T, Uehara S, Kobayashi H, Kurashina K, Yamazaki T. Squamous cell carcinoma of the tongue during pregnancy experiences in two-year treatments. Oral Oncology Extra 2005;41(01):7-11
49 Lloyd CJ, Paley MD, Penfold CN, Varadarajan V, Tehan B, Gollins SW. Microvascular free tissue transfer in the management of squamous cell carcinoma of the tongue during pregnancy. $\mathrm{Br} \mathrm{J}$ Oral Maxillofac Surg 2003;41(02):109-111

50 Prado KL, Nelson SJ, Nuyttens JJ, Williams TE, Vanek KN. Clinical implementation of the AAPM Task Group 36 recommendations on fetal dose from radiotherapy with photon beams: a head and neck irradiation case report. J Appl Clin Med Phys 2000;1(01):1-7

51 Shibuya H, Saiot M, Horiuchi JI, Suzuki S. Treatment of malignant head and neck tumors during pregnancy-a report of 3 cases. Acta Oncol 1987;26(03):237-238

52 Thorup C, Sebbesen L, Danø H, et al. Carcinoma of the nasal cavity and paranasal sinuses in Denmark 1995-2004. Acta Oncol 2010; 49(03):389-394

53 Guzzo M, Locati LD, Prott FJ, Gatta G, McGurk M, Licitra L. Major and minor salivary gland tumors. Crit Rev Oncol Hematol 2010;74 (02):134-148

54 Spiro RH. Salivary neoplasms: overview of a 35-year experience with 2,807 patients. Head Neck Surg 1986;8(03):177-184

55 Jones AV, Craig GT, Speight PM, Franklin CD. The range and demographics of salivary gland tumours diagnosed in a UK population. Oral Oncol 2008;44(04):407-417

56 Hocwald E, Korkmaz H, Yoo GH, et al. Prognostic factors in major salivary gland cancer. Laryngoscope 2001;111(08):1434-1439

57 Shah KJ, Chamoun RB. Large vestibular schwannomas presenting during pregnancy: management strategies. J Neurol Surg B Skull Base 2014;75(03):214-220

58 Sharma JB, Pundir P, Sharma A. Acoustic neuroma in pregnancy: emergency cesarean section and definitive neurosurgery. Int J Gynaecol Obstet 2003;80(03):321-323

59 Gaughan RK, Harner SG. Acoustic neuroma and pregnancy. Am J Otol 1993;14(01):88-91

60 Abike F, Bingol B, Temizkan O, et al. Primary tracheal adenocystic carcinoma and tracheal tumors during pregnancy. Rare Tumors 2011;3(03):e33

61 Stroncek GG, Dahl EC, Fonseca RJ, Benda JA. Multiosseous osteosarcoma involving the mandible: metastatic or multicentric? Oral Surg Oral Med Oral Pathol 1981;52(03):271-276

62 Ferlito A, Nicolai P. Laryngeal cancer in pregnancy. Acta Otorhinolaryngol Belg 1980;34(06):706-709

63 Pytel J, Gerlinger I, Arany A. Twin pregnancy following in vitro fertilisation coinciding with laryngeal cancer. ORL J Otorhinolaryngol Relat Spec 1995;57(04):232-234

64 Maxwell C, Barzilay B, Shah V, Wunder JS, Bell R, Farine D. Maternal and neonatal outcomes in pregnancies complicated by bone and soft-tissue tumors. Obstet Gynecol 2004;104(02):344-348 